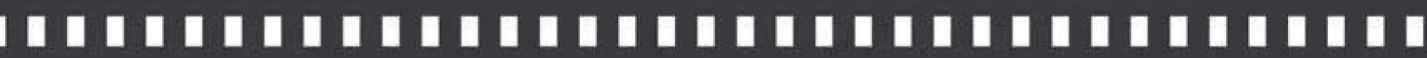 Taxonomia fotográfica: uma proposta metodológica para a pesquisa dos selfies em redes sociais

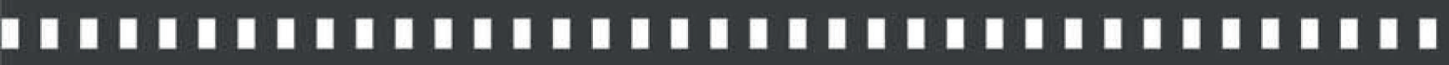

Hertz Wendel de Camargo Josemara Stefaniczen

Artigo recebido em: 18/01/2016 Artigo aprovado em: 02/12/2016 


\title{
Taxonomia fotográfica: uma proposta metodológica para a pesquisa dos selfies em redes sociais
}

\author{
Photographic taxonomy: a methodological proposal for the \\ research of selfies in social media
}

Hertz Wendel de Camarg0* e Josemara Stefaniczen**

\begin{abstract}
Resumo: As complexidades que envolvem os selfies não poderiam ser contempladas em um único artigo. Desta forma, nossos objetivos são apresentar um breve recorte epistemológico que permita uma interpretação plausivel desse gênero fotográfico e apresentar os caminhos metodológicos para a seleção de um corpus para uma possível análise do autorretrato no Instagram. Concluímos que, apesar da natureza polissêmica das redes sociais, é possível uma taxonomia do selfie aplicável a outros gêneros fotográficos circulantes na cultura midiática.
\end{abstract}

Palavras-chave: Selfie. Taxonomia. Pesquisa. Mídias sociais.

\begin{abstract}
The complexities that involve selfies could not be contemplated in a single article. Thus, our goals are to provide a brief epistemological framework that allows a plausible interpretation of this photographic genre and to present the methodological approaches to the selection of a corpus for a possible self-portrait analysis on Instagram. We conclude that, despite the polysemic nature of social networks, it is possible a taxonomy of selfie applicable to other current photographic genres in media culture.
\end{abstract}

Keywords: Selfie. Taxonomy. Research. Social media.

* Doutor em Estudos da Linguagem (Universidade Estadual de Londrina UEL); mestre em Educação, Conhecimento, Linguagem e Arte (Universidade Estadual de Campinas - UNICAMP); professor permanente do Programa de PósGraduação em Comunicação da Universidade Federal do Paraná (PPGCOMUFPR); professor colaborador do Programa de Pós-Graduação em Letras da Universidade Estadual do Centro-Oeste (PPGL-Unicentro); professor do curso de Publicidade e Propaganda da UFPR. Líder do grupo de Estudos em Comunicação, Consumo e Sociedade (ECCOS-UFPR) 


\section{Introdução}

Em uma descompromissada observação do Instagram, verificamos que a experiência do selfie proporciona um renovado poder de sedução da fotografia sobre as pessoas ao manter no ciberespaço a mesma "[...] relação de especialista com o mundo e uma promíscua aceitação do mundo" (SONTAG, 2004, p. 96). Isto é, as pessoas, ao se considerarem dominantes de um tipo de fotografia, imaginariamente, julgam-se fotógrafas. Já o público em geral, quando visualiza (consome) tais produções fotográficas nas redes - em grande parte por falta do conhecimento sobre o que é a fotografia, sua linguagem e técnicas - acaba por aceitar toda a imagem como fotografia (arte), portanto, reforça a ideia do amador como pretenso fotógrafo.

Em outros termos, com o fácil acesso a diferentes tecnologias de registro, de upload de imagens e mídias sociais, os sujeitos saem do anonimato e tornam-se fotógrafos potenciais, em constante vigia do mundo, prontos para traduzir, em objeto fotográfico, infinitas experiências com a realidade. Entretanto, quando o objeto retratado passa a ser o próprio sujeito significa inúmeros devires, fazendo do privado - o doméstico, o corporal, o subjetivo, o íntimo - objeto (ou estilo de vida) a ser devorado como e pela imagem. "Assim, a fotografia se transforma em um impor $\neg$ tante instrumento de comunicação, de registro cotidiano, de visualização da existência e de construção identitária" (CRUZ; ARAÚJO, 2012, p. 112).

Criado por Kevin Systrom e Mike Krieger, lançado em outubro de 2010, o Instagram contribuiu para a popularização do selfie $^{1}$, fenômeno amplamente disseminado nas mídias sociais,

** Mestre em Letras pelo Programa de Pós-Graduação em Letras - área de concentração "Interfaces entre Língua e Literatura", linha de pesquisa "Texto, Memória e Cultura", pela Universidade Estadual do Centro-Oeste (Unicentro, 2016). Graduada em Letras pela Universidade Estadual do Centro-Oeste (Unicentro, 2004). Membro do grupo de Estudos em Comunicação, Consumo e Sociedade (ECCOS-UFPR)

1 O termo selfie deriva da palavra inglesa self-portrait e significa um 
afetando com o mesmo poder de sedução pessoas públicas e anônimas. Ao realizar a busca no Instagram pelas palavras-chave selfie, selfies e selfienation, antecedidas por hashtag (\#) e a título de experiência, obtém-se um número próximo a 305 milhões $^{2}$ de publicações. Não estão inclusas outras mídias sociais e aplicativos como o SnapChat, Happn, Tinder, Grindr, Badoo e Blendr, ou os blogs e sites especializados. Todos constituem novos, amplos e velozes canais de distribuição da fotografia que, como apontaram Cruz e Araújo (2012), estava destinada à morte iminente ou ao deslocamento à margem da cultura.

O fenômeno - que inclui produzir, registrar, editar e publicar um autorretrato digital em mídias sociais - é mais que apenas um modismo da cibercultura. Hoje, os selfies, além de configuração da estética e da linguagem do cotidiano, são um sintoma da cultura, pois revela nossa relação com as imagens, o imaginário e, principalmente, com a nossa construção identitária no espaço social, agora, mediado pelas tecnologias. Entretanto, publicar imagens de si nas mídias sociais parece uma atividade inocente, quase sempre reconhecida como banalidade ou comportamento de quem tem uma necessidade pungente de se exibir para o outro. Entretanto, o selfie não pode ser visto apenas em sua materialidade imagética, estudado unicamente como um autorretrato digital. Para tanto, o selfie além de ser uma imagem técnica, deve ser abordado como experiência. Justificamos o termo "experiência" no sentido de experimentação, pois, é isso que faz cada sujeito por trás de um perfil de mídia social. O chamado "ator social" (RECUERO, 2009) experimenta, cria, reinventa a si mesmo. O conceito de "experiência do selfie" carrega a ideia de identidade em processo de composição, uma busca constante pela experimentação visual,

autorretrato produzido por celular, webcam ou câmera digital e compartilhado pelas mídias sociais.

2 Para a busca de \#selfie: 282.476 .807 de publicações; para \#selfies: 17.196.215 de publicações; \#selfienation: 5.219.146. Junto, têm no total de 304.892.168 de publicações no Instagram. Pesquisa em 10 de jun. de 2015. Certamente, hoje estes números são diferentes. 
cênica, narratológica, performática. A experiência do selfie significa performance identitária, isto é, identidade em constante processo de construção, obra eternamente inacabada.

Figura 1 - Painéis retirados aleatoriamente do Instagram, por celular, a partir da hashtag \#selfienation
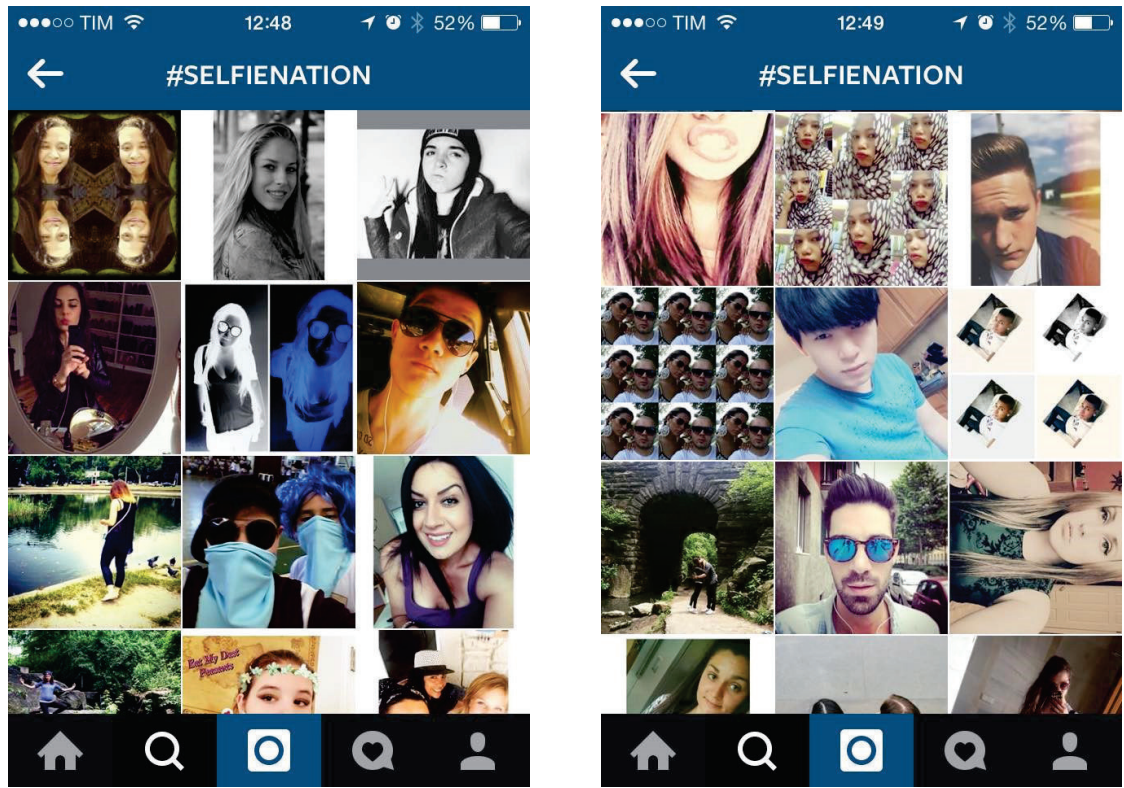

Fonte: Instagram (2015)

Pensar o selfie como experiência que nunca chega ao fim uma redundante experimentação de máscaras pelos diversos atores sociais - corrobora Hall (2003) ao constatar que as identidades estão sendo descentradas, deslocadas, fragmentadas e que, após o sujeito iluminista (centrado e inteiro) e o sujeito sociológico (estável em suas identidades culturais) vivenciamos por meio das mídias sociais o sujeito pós-moderno que perdeu a solidez (ou permanência) de sua identidade. Conforme Villaça (2002), para o sujeito pósmoderno, a identidade passa a ser experimentada como "uma 
celebração móvel que se transforma em relação às formas pelas quais somos representados e interpelados nos sistemas culturais que nos rodeiam" (VILLAÇA, 2002, p. 2). Portanto, as imagens "[...] que povoam nossos meios imagéticos se constituem, em grande parte, de ecos, repetições e reproduções de outras imagens, a partir do consumo das imagens presentes no grande repositório" (BAITELLO JUNIOR, 2005, p. 54).

Desse modo, a experiência do selfie envolve uma rede de sentidos produzidos antes (sob influência de memórias e do imaginário), durante (sob influência das tecnologias e linguagens) e após sua publicação, quando participa de uma educação visualestética do olhar do outro em relação a usos, discursos e visualidades dos corpos, das máscaras, das identidades e das formas de ser e estar em rede/sociedade. Portanto, o selfie representa claramente o que McCracken (2007) descreve como trajetória do significado: do mundo culturalmente constituído para o selfie nas redes sociais e do selfie para o consumidor das imagens, retornando à cultura. Em meio a toda essa natureza polissêmica propomos uma metodologia para a seleção e taxonomia dos autorretratos presentes nas redes sociais, especialmente o Instagram. Antes, traçaremos uma breve episteme relacionada a esse gênero fotográfico.

\section{A episteme dos autorretratos digitais}

A complexidade desses autorretratos envolve várias questões que passam pelas relações entre identidade e corpo, público e privado, consumo e imagem, culto e imagem, controle e estimulação, realidade e simulacro, máscara e performance. Tais relações são permeadas por uma narrativa que tem como protagonista um $\mathrm{Eu}$ - construído, performático, objetificado. O selfie auxilia na composição de uma identidade, portanto, seu discurso é atravessado por narrativas que dão sentido e expressão às relações de consumo em nossa sociedade. Ao mesmo tempo, o consumo do selfie representa a dinâmica da cultura contemporânea, 
concomitantemente líquida (BAUMAN, 2001), narcísica (LASCH, 1983), performática (GOFFMAN, 1985) e, acima de tudo, iconofágica (BAITELLO JUNIOR, 2005).

Complexos, multidimensionais, polifacetados, amplos. Os temas que envolvem os autorretratos nas mídias sociais não poderiam ser aprofundados ou simplesmente envolvidos na sua totalidade em um único artigo. Não pretendemos explorar as várias possibilidades do objeto em si, mas apresentar um olhar, uma interpretação plausível para o selfie, de forma geral pautado em diferentes vertentes da Antropologia, pois, se trata de uma ciência que

[...] possui um diferencial interpretativo importante para contribuir no diálogo que deve caracterizar a pesquisa sobre o imenso repertório de imagens, identidades, representações, simbolismos e sistemas de classificação que é disponibilizado através disso que chamamos indústria cultural (ROCHA, 2001, p. 16).

Sobre as contribuições da Antropologia para a interpretação do fenômeno, e por se tratar de uma área de conhecimento cada vez mais especializada, optamos cruzar duas vertentes da Antropologia Cultural: a Antropologia Visual e Antropologia do Consumo esta uma vertente da Antropologia Urbana. Tradicionalmente, a Antropologia Visual é dedicada à análise da imagem - especialmente a fotografia e o cinema - bem como os processos de sua produção, utilizados como documentos/registros etnográficos. Também envolve o estudo das representações visuais nos rituais, na produção e recepção da mídia de massa, nos museus, nos espetáculos e nas artes. Desde o surgimento da internet, em meados dos anos 1990, a Antropologia Visual também voltou sua atenção às novas mídias e aos multimeios.

A Antropologia do Consumo também figura como importante campo para a interpretação do selfie como expressão da 
cultura. A aproximação com essa vertente se dá por meio dos bens e experiências de consumo cuja principal narrativa é a publicitária. A publicidade estrutura o sistema da mídia, mantém vivos os mitos, magias e rituais do cotidiano nas cidades e nas práticas sociais contemporâneas. Para Rocha (2006), a publicidade é "“[...] a narrativa que dá sentido ao consumo, e está seguramente, entre as principais produtoras de sistemas simbólicos presentes em nosso tempo". O selfie protagoniza uma narrativa que traduz o Eu em alteridade e, durante sua recepção (primeiro pelo sujeito, em seguida pelo público), ocorre um processo de materialização/objetificação do sujeito em objeto fotográfico, criando uma identidade a partir de uma máscara performática, pronto para ser consumido. O sentido de "bem de consumo" não se restringe a produtos e serviços e deve ser ampliado igualmente para tudo que promove as trocas simbólicas (e diabólicas) entre as pessoas, tais como as relações humanas, discursos, comportamentos, rituais, totens, mídias e suas imagens. A lógica da publicidade se pauta na visualidade, na narrativa, no pensamento mágico-totêmico, na ritualização e reatualização dos mapas culturais por meio do consumo de categorias e princípios culturais concretizados em objetos (bens) de diferentes naturezas (MCCRACKEN, 2007). É justamente essa lógica que está presente nos processos de produção, distribuição e consumo dos selfies.

Portanto, os conceitos de Baitello Junior (2005) sobre iconofagia, representam um ponto de encontro entre a Antropologia Visual e a do Consumo visto que, atualmente, vivenciamos o terceiro estágio de devoração - as imagens devoradoras do homem - verificado na experiência do selfie. Segundo o autor, existem três etapas da iconofagia: "[...] na primeira, imagens devoram imagens; na segunda etapa, homens devoram imagens; e a última, imagens devoram os homens" (BAITELLO JUNIOR, 2005, p. 53-55).

Devemos, ainda, considerar a estética performática do selfie, no sentido de criação de um Eu idealizado mediado, concomitantemente, pela moldura fotográfica e a rede social, incitando o "jogo de cena" entre os atores sociais. Segundo Goffman 
(1985), na vida social, os sujeitos são hábeis em escolher seu palco, sua história, seu figurino conforme o público com o qual interagem, procurando sempre manter a coerência, promovendo ajustes no decorrer da interação com outros atores sociais.

[...] os habitantes desses espaços montariam espetáculos de si mesmos para exibir uma intimidade inventada. Seus testemunhos seriam, a rigor, falsos ou hipócritas: não autênticos. [...] Apesar do pantanoso que parece esse terreno, ainda assim cabe indagar se todas essas palavras e essa enxurrada de imagem não fazem nada mais (e nada menos) do que exibir fielmente a realidade de uma vida nua e crua (SIBILIA, 2008, p. 29-30).

De qualquer forma, nos ritos sociais contemporâneos, podemos considerar que ocorre sempre um deslocamento temporal duplo - tanto por parte dos sujeitos quanto do público. Segundo Schechner (1985), um deslocar-se de um tempo real/histórico/ ordinário para o tempo fantástico/a-histórico/extraordinário do ritual ou cerimônia encenada, um deslocamento momentâneo que cessa ao fim da performance. Portanto, o selfie encerra em si o mesmo deslocamento temporal duplo no qual o sujeito se desloca do tempo histórico/real para dentro do tempo fantástico/ imaginal do selfie. Dentro da moldura fotográfica estão presentes a máscara, a cena, a narrativa, a ação, a ficção, o personagem, ou seja, os elementos organizados em uma estrutura sígnica próxima da performance teatral a serviço da performance social mediada pela tecnologia, da composição de uma identidade associada a um determinado estilo de vida. O espaço quadrangular do selfie é, pois, um tipo de palco que se insere em um contexto maior, outro palco, as redes sociais. 


\section{Por uma taxonomia do selfie: caminhos metodológicos}

Os caminhos metodológicos para a seleção do corpus e posterior categorização das imagens cumpriram as seguintes etapas:

I. ETAPA 1 (entre abril de 2014 e dezembro de 2014) - Uma pesquisa exploratória foi necessária para compreender o selfie em sua genealogia visual/narrativa e suas bases antropológicas, para lançar luz sobre a pulsão por trás desse fenômeno cultural. Como não se trata de um fenômeno novo, buscamos artigos, pesquisas sobre consumo de mídia, dissertações e teses, como leituras preliminares para a elaboração de questões para duas pesquisas aplicadas. Para estudar o fenômeno, realizamos uma pesquisa qualitativa, com questionário online, divulgada exclusivamente pelo Facebook, onde os entrevistados foram convidados a refletir e opinar sobre a prática da produção, a disseminação e os sentidos despertos pelos selfies. Responderam ao questionário um total de 144 entrevistados de diferentes estados do Brasil, sendo dois brasileiros moradores nos Estados Unidos (EUA). Em seguida, foram realizadas duas entrevistas (pesquisa narrativa) com dois informantes, considerados, em nossa visão, totalmente inseridos na selfie culture ${ }^{3}$, selecionados a partir do monitoramento de um mês (de 01/06/2014 a 01/07/2014) dos seus perfis no Facebook e Instagram, sendo um do sexo masculino e outro do feminino, de distintos centros urbanos do Paraná. Foram dois critérios de seleção desses sujeitos: raramente passar um dia sem publicar, pelo menos, um selfie em seu perfil; e acessar a internet por mais de cinco horas diárias ${ }^{4}$. Em relação a essa abordagem metodológica, consideramos

3 Termo da imprensa americana que descrever o momento cultural em que vivemos a ampla e indiscriminada disseminação de selfies por pessoas comuns e figuras públicas em redes sociais.

$4 \quad$ Esse tempo foi estipulado conforme a Pesquisa Brasileira de Mídia 2014 - que apresentou resultados referentes ao ano de 2013 - publicada pelo Governo Federal. Segundo a PBM 2014, os usuários das novas mídias permaneciam conectados, em média, $3 \mathrm{~h} 39$ por dia durante a semana e $3 \mathrm{~h} 43$ por dia nos fim de 
que as histórias narradas individualmente foram autobiográficas, reveladoras de identidades e deram oportunidade aos entrevistados para descrever a imagem que possuem de si mesmos. Concluímos, com a pesquisa aplicada e as entrevistas, que o selfie é um novo gênero fotográfico, pois possui características estéticas facilmente identificadas pelos entrevistados como uma fotografia produzida em momentos quando se está só ou em grupo sem a necessidade da presença de um fotógrafo $(35,2 \%)$; uma fotografia que expressa e compartilha a felicidade do sujeito (22,5\%); uma fotografia que ostenta dotes, qualidades e bens de consumo $(21,1 \%)$; uma fotografia que remete à valorização do sujeito, buscando sua autoestima por meio da melhor imagem (11,3\%); somando 9,2\% identificam o selfie como uma expressão narcísica do sujeito; e apenas $0,7 \%$ afirmam que o selfie não possui função estética. As frases mais emblemáticas dos informantes nas entrevistas foram: “[...] o selfie representa na minha concepção uma construção além da minha identidade" (gênero masculino, 30 anos); "[...] não gosto de como saio em fotos tiradas por outras pessoas, geralmente eu não fico bem, por isso gostos das selfies, consigo arrumar o ângulo certo e a luz pra me deixar mais bonita" (gênero feminino, 25 anos).

II. ETAPA 2 (entre janeiro/2015 e maio/2015) - Leituras complementares de livros específicos da área de antropologia visual, antropologia do imaginário, antropologia do consumo, estudos sobre o ritual, performance, entre outros autores e pesquisas da área de antropologia para a composição do campo epistêmico em torno do selfie.

III. ETAPA 3 (entre os dias 06 e 27 de abril/2015, definição do corpus) - Nesta etapa, em paralelo à segunda etapa, definimos a mídia social onde buscaríamos os selfies. Conforme a pesquisa encomendada pela Secretaria de Comunicação do Governo Federal (BRASIL, 2014), em relação às mídias sociais, a preferência dos

semana. Na PBM 2015, referentes entrevistas realizadas em 2014, os números passaram para $4 \mathrm{~h} 59$ por dia durante a semana e $4 \mathrm{~h} 24$ por dia nos finas de semana (BRASIL, 2014, p. 7). 
entrevistados segue a seguinte distribuição percentual: Facebook (83\%), Whatsapp (58\%), YouTube (17\%), Instagram (12\%), Google+ $(8 \%)$ e Twitter (5\%). De todas as redes apontadas na pesquisa, optamos em observar os selfies publicados no Instagram por se tratar de uma mídia social em que as imagens possuem pouca concorrência entre o visual e o verbal. No Instagram, as imagens são exibidas quase de forma exclusiva ao usuário/observador, podem ter ou não uma legenda que agrega outros sentidos à imagem representando uma célula diegética formada entre um texto visual e um texto verbal. Em outros termos, diferente das demais, essa mídia é um pouco menos "barroca". Outra justificativa é que o Instagram possui uma estrutura tecnológica diretamente adaptada ao consumo por celular, com rápido acesso e facilidade de upload, uma mídia totalmente adaptada para a experiência do selfie. Além disso, o Instagram proporciona um espaço de performance - no sentido descrito por Goffman (1985) - bastante personalizado. Outra razão para a escolha dessa mídia, é que ela possibilita a busca categorizada de tipos ou estilos de selfies a partir do símbolo hashtag (\#). Em uma pesquisa rápida, por meio das palavras-chave \#selfie, \#selfies e \#selfienation encontramos quase 305 milhões de ocorrências mundiais.

VI. ETAPA 4 (entre 01/maio e 30/junho de 2015) - Diante de todas essas possibilidades de pesquisa, passamos a buscar padrões de produção, estilos e temas nos selfies publicados no Instagram. Verificamos a recorrência dos seguintes temas, conforme os objetos fotográficos: partes do corpo, animais de estimação, bebês, fotos de alimentos e fotos na frente do espelho ${ }^{5}$. Optamos em categorizar, para futura análise, os selfies produzidos frente ao espelho. Justificamos a escolha por verificarmos, em nossas explorações, que esse objeto cotidiano, o espelho: a) permite, por parte do sujeito, um controle maior do processo de produção do

5 As coisas e os seres que pertencem à intimidade do sujeito e podem se tornar objetos fotográficos são considerados selfies na medida em que são extensões do seu corpo e/ou do seu Eu. 
selfie; b) estimula a invenção e a performance do sujeito perante três representações identitárias imagéticas: a imagem no espelho, a fotografia digital e a imagem publicada na mídia social; c) representa um objeto em conexão direta com a memória cultural, o imaginário e as narrativas míticas, especialmente relacionadas ao personagem Narciso - emblema de culto à própria imagem. Realizamos, então, uma busca por meio do celular (smartphone) por hashtags com palavras relacionadas ao termo espelho nos idiomas espanhol e inglês, já que o termo selfie já é bastante disseminado entre diferentes idiomas e culturas. O objetivo, nessa parte da pesquisa, foi explorar aleatoriamente as ocorrências globais, mesmo sabendo que as regionalidades devem ser consideradas como lentes e/ou mapas culturais influentes tanto no consumo quanto na produção de tais imagens, ou seja, na movimentação dos significados do mundo culturalmente constituído (MCCRACKEN, 2007), para as imagens nas redes e, finalmente, para receptores (consumidores) dessas produções. Com oito hashtags onde constam termos como selfie, mirror e espejo, obtivemos 16.037.751 de ocorrências mundiais. Para cada hashtag selecionamos os primeiros 10 painéis, sendo que cada painel apresentou 9 imagens inteiras ${ }^{6}$ num total de 720 imagens selecionadas na amostragem. Em relação ao número total de ocorrências mundiais, a soma de todas as oito hashtags pesquisadas, o número analisado de 720 imagens é ínfimo, não chega a $1 \%$ do total (cerca de 160.377 imagens), o que seria inviável por questões técnicas e de tempo para este artigo. Assim, reiteramos que o objetivo desta pesquisa é apontar uma metodologia viável para a classificação de selfies numa rede social cujos resultados são alterados conforme variáveis como idioma, cultura, regionalismos, contexto histórico, sistema de moda, tecnologia, podendo baixar, consideravelmente, o número da amostragem. Assim expostos tais apontamentos, apresentamos o seguinte resultado:

$6 \quad$ Os smartphones utilizados para a pesquisa são do modelo Iphone 4s. Esse modelo possui tela de 3,5 polegadas. Se outros modelos, com telas maiores, forem utilizados, o número de imagens por painel pode variar. 
Quadro 1 - Busca por hashtags com palavras relacionadas a espelho e selfie

\begin{tabular}{|c|c|c|c|}
\hline Busca & $\begin{array}{c}\text { Número de } \\
\text { publicações }\end{array}$ & $\begin{array}{c}\text { Painéis } \\
\text { selecionados }\end{array}$ & Fotos \\
\hline \#mirror & 12.541 .744 & 10 & 90 \\
\hline \#mirrorpic & 2.036 .243 & 10 & 90 \\
\hline \#mirrorselfie & 1.382 .471 & 10 & 90 \\
\hline \#selfiemirror & 34.704 & 10 & 90 \\
\hline \#fitnessselfie & 25.212 & 10 & 90 \\
\hline \#mirro & 15.854 & 10 & 90 \\
\hline \#selfieespejo & 911 & 10 & 90 \\
\hline \#selfiemirrorpic & 612 & 10 & 90 \\
\hline Total & $\mathbf{1 6 . 0 3 7 . 7 5 1}$ & $\mathbf{8 0}$ & $\mathbf{7 2 0}$ \\
\hline
\end{tabular}

Fonte: Elaborado pelos autores $(2015)^{7}$

De forma geral, verificamos que os selfies com o uso do espelho possuem um grande número de ocorrências globais (no total, mais de 16 milhões $^{8}$ ). Para a taxonomia fotográfica, identificamos padrões temáticos, visuais, performáticos, tecnológicos e estéticos de autorretratos com o uso de espelhos, dividindo-os em grupos.

\section{Uma taxonomia fotográfica: proposta de classificação de selfies}

Os selfies produzidos frente ao espelho são mais que uma ocorrência comum no Instagram. São, na verdade, um indicativo do consumo ritual (do sempre igual) desse gênero fotográfico, indicando o ciclo redundante do trânsito de significados em três espaços distintos: do mundo culturalmente constituído para o selfie, deste para os consumidores (MCCRACKEN, 2007) e, por fim, a

$7 \quad$ Consulta em 10 de junho de 2015.

8 Este número é o pesquisado em 10 de julho de 2015. Certamente, se realizadas as mesmas buscas, o Instagram apresentará novos números. 
partir destes retorna à cultura. Portanto, a repetição é um traço do ritual presente em muitas instâncias da produção fotográfica e faz do "frente ao espelho" um tema obsedante na experiência do selfie no Instagram. O principal critério de categorização em nossa pesquisa se deu, justamente, por meio da repetição visual - entre as 720 imagens analisadas - de temas, padrões estéticos, discursos visuais, expressões corporais, aplicação de recursos de edição, objetos, apresentando os seguintes resultados:

Quadro 2 - Distribuição das imagens frente ao espelho em tipologias

\begin{tabular}{|lc|c|}
\hline \multicolumn{2}{|c|}{ Tipologia dos Selfies } & Ocorrências \\
\hline 1. & Cotidiano & 167 \\
\hline 2. & Moda & 123 \\
\hline 3. & Fitness & 115 \\
\hline 4. & Especular & 86 \\
\hline 5. & Caleidocópico & 79 \\
\hline 6. & Sequencial & 72 \\
\hline 7. & Artístico & 56 \\
\hline 8. & Outros & 22 \\
\hline & Total & $\mathbf{7 2 0}$ \\
\hline
\end{tabular}

Fonte: Elaborado pelos autores (2015)

O hábito do sujeito de registrar a imagem de si, analisar, consumir-se, aprovar ou descartar, refazer se necessário, aplicar filtros, publicar e acompanhar os likes - bem como o retorno diário a esse processo - todas essas ações representam, ao mesmo tempo, um padrão técnico e comportamental repetido por todos que se habilitam a postar autorretratos no Instagram. O publicar diariamente selfies, checar as mensagens, comentários e "curtidas" de seu perfil e de outros sujeitos são, ritualisticamente, repetitivos. A partir desses apontamentos, criamos sete categorias que servirão como guias para análises futuras. Elas foram catalogadas e descritas da seguinte maneira: 
1) Selfie Cotidiano - A maioria dos autorretratos estudados (cerca de 23\%) são registros de cenas corriqueiras dos usuários, em atividades relativamente simples do dia-a-dia, aproveitando o encontro casual com o espelho, em locais públicos, elevadores, recepções, áreas comuns em prédios, situações caseiras.

Figura 2 - Selfies de cenas cotidianas
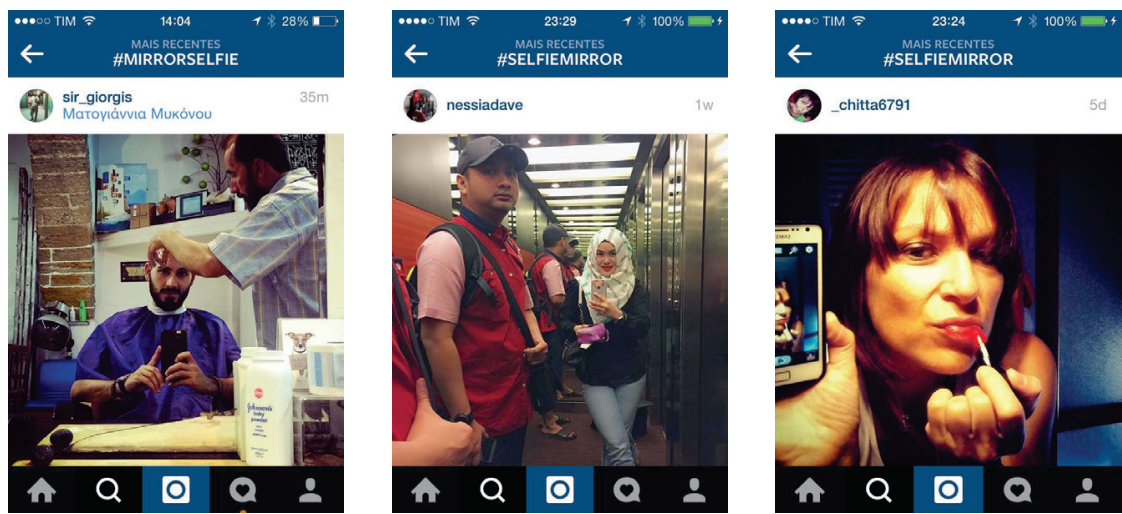

nessiadave

_chitta6791
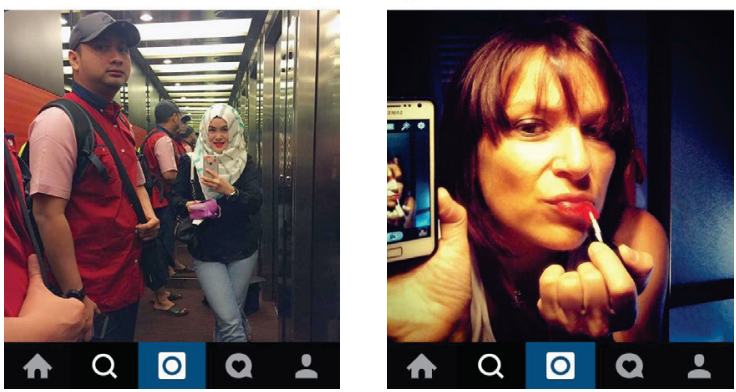

Fonte: Instagram (2015)

2) Selfie de Moda - Nestas imagens (17\% das ocorrências da amostragem) os sujeitos têm por objetivo registrar uma composição de trajes, ostentar produtos e marcas de grife, dar dicas de como se vestir ou, simplesmente, documentar um momento em que a roupa traduz seu estado de espírito. 
Figura 3 - Selfies de moda
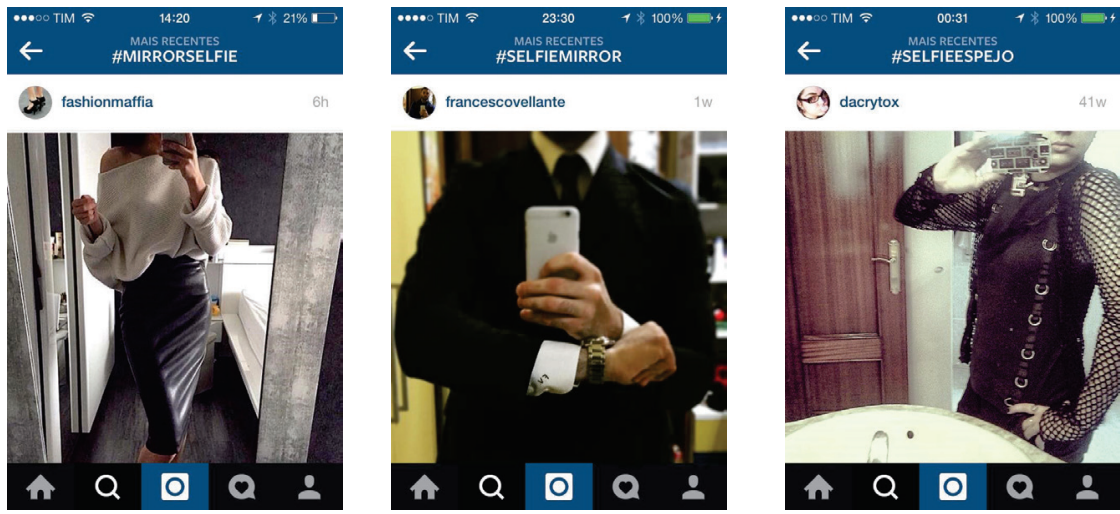

(2). dacrytox

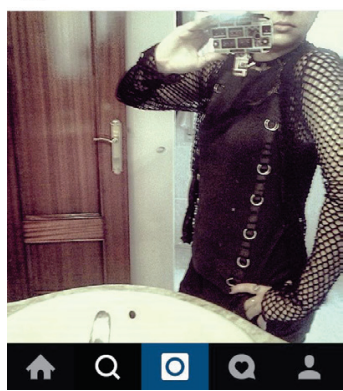

Fonte: Instagram (2015)

3) Selfie de Fitness - Essa categoria (perto de 16\%) é representada por sujeitos que registram a evolução corporal a partir de atividades físicas, o que torna esse tipo autorretrato frente ao espelho bastante comum. As imagens também revelam sujeitos que ostentam seus corpos esculpidos em academias como "produtos" arduamente conquistados, beirando a sensualidade e, muitas vezes, o erotismo.

Figura 4 - Selfies de fitness
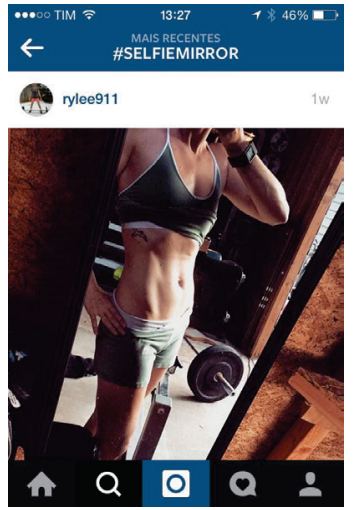

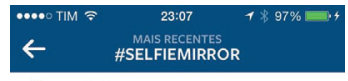

(B) michelroversi

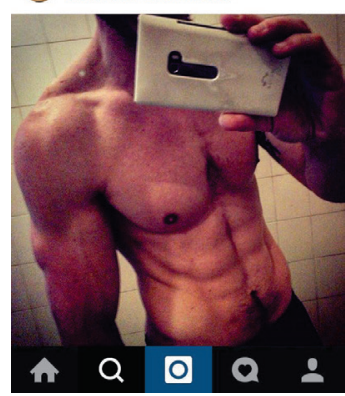

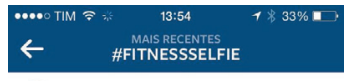

3indmyhalo

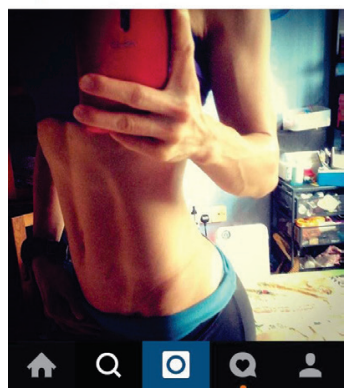

Fonte: Instagram (2015) 
4) Selfie Especular - Diferente de outros autorretratos, próximo de $12 \%$, as imagens apresentam o espelho como um personagem (protagonista ou coadjuvante) da narrativa identitária, revelando o objeto e, em muitos casos, referenciando o mito de Narciso.

Figura 5 - Selfies em que o espelho é personagem

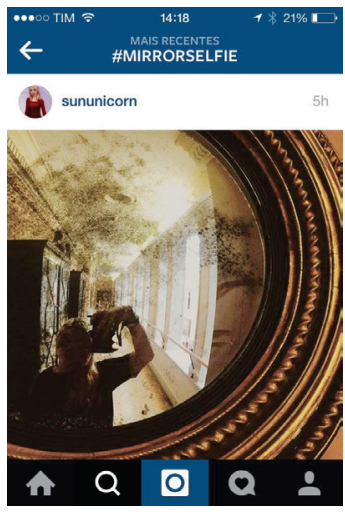

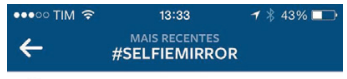

(2) nicolka

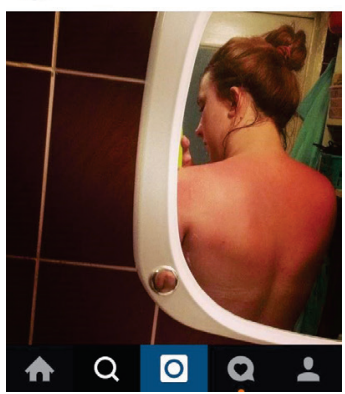

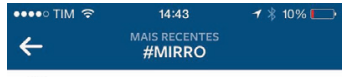

7. jahdielorozco

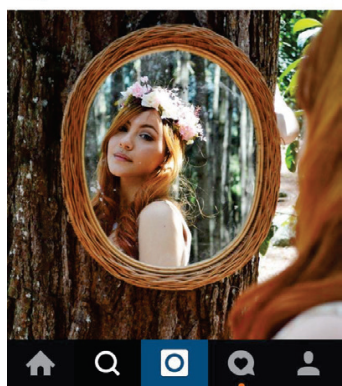

Fonte: Instagram (2015)

5) Selfie Caleidoscópico - Cerca de $11 \%$ das imagens, por meio de aplicativos de edição, os sujeitos, após se fotografarem frente ao espelho, optam em espelhar suas imagens uma ou mais vezes (o duplo - o reflexo - é ampliado, estendido, multiplicado), criando um efeito de caleidoscópio que sugere, inconscientemente, tanto uma identidade multifacetada quanto refletem as culturas igualmente fragmentadas e líquidas. 
Figura 6 - Selfies em efeito caleidoscópico

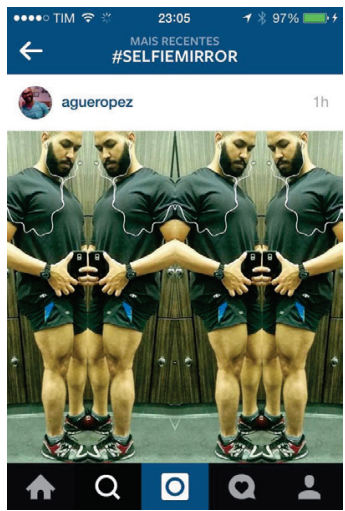

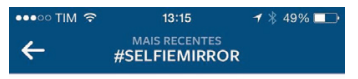

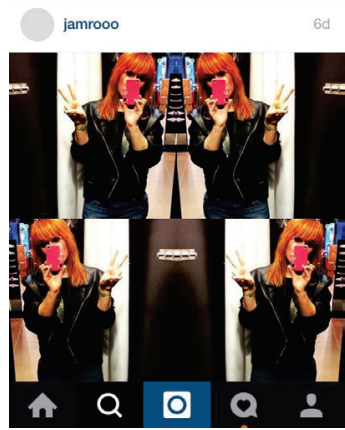

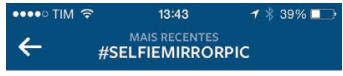

(1) emyyins

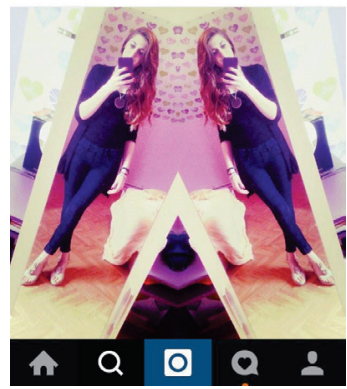

Fonte: Instagram (2015)

6) Selfie Sequencial - Assim como a classificação anterior, por meio de aplicativos de edição, em 10\% das ocorrências da amostragem, o sujeito cria uma sequência de imagens de si no mesmo enquadramento da foto do Instagram. O efeito principal é a criação de uma narrativa, dentro da moldura fotográfica, muito próximo da estrutura narrativa dos quadrinhos. Nestes casos, começo, meio e fim se misturam ou não estão bem definidos. Interessa observar que, assim, como os selfies caleidoscópicos, o recurso tecnológico permite combinações e efeitos em uma sugerida ludicidade da edição dentro da suposta inércia da imagem fotográfica. No entanto, a opção por essa estética fotográfica, apesar de ser pautada em aplicativos específicos, revela um processo de seleção, edição, enfim, de intenção do autor do selfie. 
Figura 7 - Selfies em imagens sequenciais

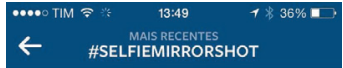

jamikeelileng

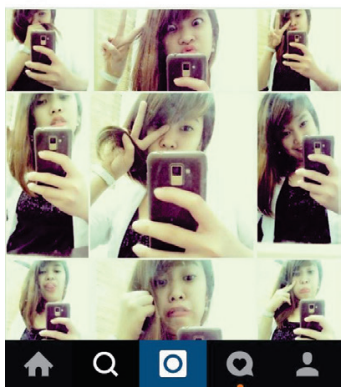

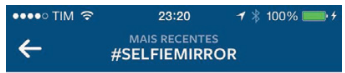

(1) maca8648

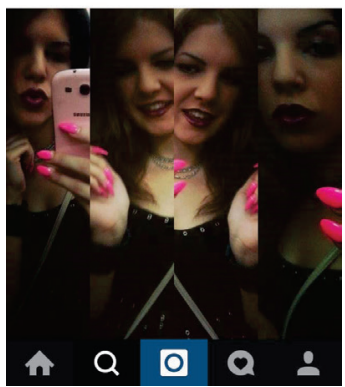

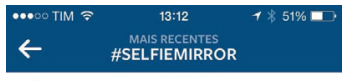

42. rinamaliamalda

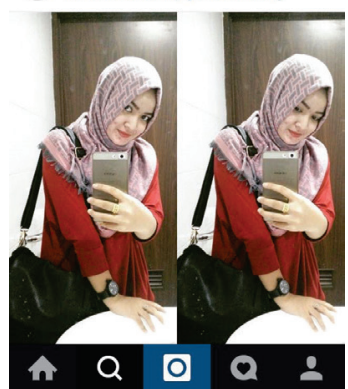

Fonte: Instagram (2015)

7) Selfie Artístico - Próximo de $8 \%$ das imagens, por meio da seleção, domínio e aplicação de outras artes e linguagens mobilizadas para compor o signo fotográfico, o usuário usa a criatividade para compor, narrar e dar sentido à sua identidade, buscando a fuga do lugar-comum.

Figura 8 - Selfies em efeitos artísticos

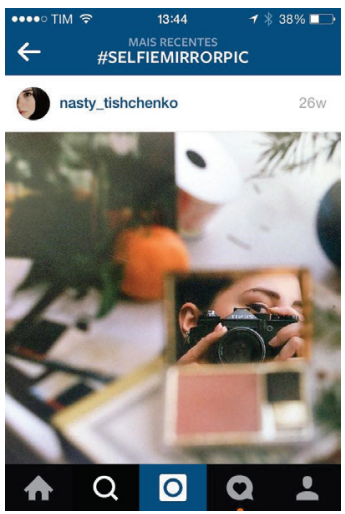

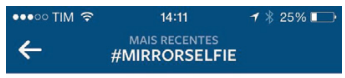

(7) darcyxmae

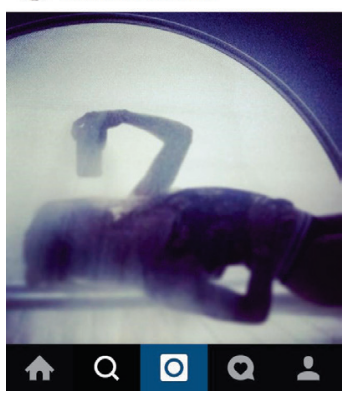

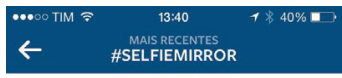

(8) anna_s_koroleva

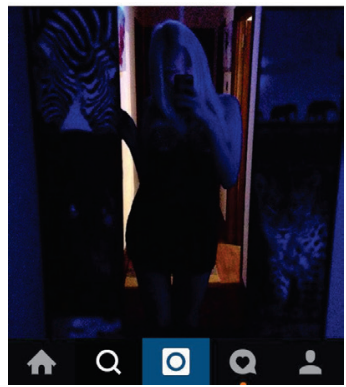

Fonte: Instagram (2015) 
8) Outras categorias - Evidentemente, outras categorias de selfies (cerca de 3\% da amostragem) com o uso do espelho foram encontradas, mas não catalogadas. Os exemplos ficam por conta dos autorretratos em que o sujeito interpreta um personagem da cultura de massa, exibe extrema sensualidade ou erotismo, ou selfies tutoriais de cabelos ou maquiagens. Até mesmo as categorias aqui apresentadas podem se misturar e imagens serem catalogadas em mais de uma categoria. Com isso, optou-se em não catalogar em uma categoria específica imagens consideradas "híbridas", que não se enquadram nas demais categorias ou com temas menos redundantes.

\section{Considerações finais}

O selfie, fenômeno comum para a maioria das pessoas que possuem perfil e acesso às mídias sociais, faz das redes e mídias sociais o espaço favorável à construção, exposição e consumo de identidades, um espaço de circulação de significados. Desse modo, os sujeitos se reinventam a partir de seus autorretratos, denotando que a fotografia tece uma narrativa identitária, reunindo e demarcando sentidos determinados pelos sujeitos. Desta forma, o selfie se tornou a comprovação dos papéis móveis dos "atores sociais" envolvidos nas relações sociais mediadas pela internet e um emblema da dinâmica das atuais interações sociais. O selfie é um sintoma da cultura.

Essas imagens, ao ocuparem o papel de máscara, na representação do Eu, são criadas e selecionadas de modo a configurar cenas, cenários, personagens de uma narrativa autobiográfica, com uma linguagem do privado e do cotidiano. $\mathrm{O}$ centro dessas narrativas é ocupado por selfies que representam seus sujeitos e apresentam temas, estilos de vida e ambientes que se repetem, indicando uma ritualização das representações do Eu, do seu cotidiano e das suas atividades, bem como uma classificação plausível para as imagens do Instagram. 
Verificamos, também, que é muito clara a presença do mitema da tomada de consciência de si - a partir do encantamento com a própria imagem (identidade) - como memória estrutural na narrativa dos selfies. A aproximação com o mito de Narciso se dá quando os autorretratos possuem a presença do espelho, emblema do amor por si mesmo. Assim como o personagem do mito, os sujeitos perdem sua identidade original em detrimento da imagem ideal, no caso, de uma identidade (máscara) julgada como perfeita e verdadeira, por mais performática que esta seja. A imagem ganha mais sentido, mais importância, uma alteridade bem maior que o sujeito, tomando o lugar ou se distanciando do Eu original ("cultura do eco", BAITELLO JUNIOR, 2005). Assim, Narciso, ensimesmado, torna-se uma extensão da imagem e não o contrário. Devorado pela imagem, o sujeito torna-se uma parte do autorretrato, como se o sujeito fosse a representação do selfie e não o contrário.

Deste modo, em tempos de iconofagia, produzir um selfie significa tornar-se imagem e, assim, devorar-se e ser devorado pela imagem. É neste ponto que reside a "microexperimentação da morte", narrada por Barthes (2000). Por um lado, consumir a imagem significa destruir o que foi criado; por outro lado, ser consumido pela imagem significa entregar-se ao sacrifício para um imaginário bem maior: renascer em nova identidade. Excluso o primeiro autorretrato, que teve como base um Eu mais próximo do real, todos os posteriores a esse primeiro são máscaras originadas de outras máscaras. Cópias da cópia, ecos do eco, ad infinitum.

[...] em toda imagem existe uma referência às imagens que a precederam. [...] toda imagem se apropria das imagens precedentes e bebe nelas ao menos parte de sua força. [...] A força de uma imagem provém de seu lastro de referências a outras tantas imagens (BAITELLO JUNIOR, 2005, p. 95). 
Portanto, há uma sutil diferença identitária no antes e no depois do selfie. A cada autorretrato, um novo Eu agrega mais sentidos ao $\mathrm{Eu}$ anterior - que também era máscara. Cada selfie publicado representa o que Baitello Junior (2005) chamou de "lógica do eco", em uma cultura iconofágica ocorre a apropriação das imagens antecedentes ou a "[...] repetição das sílabas finais, dos sons finais, das impressões finais e superficiais. Não há memória profunda, há apenas memórias epidérmicas. [...] sem memórias viscerais" (BAITELLO JUNIOR, 2005, p. 52).

Concluímos que, apesar da natureza polissêmica das redes sociais, é possível uma taxonomia do selfie que pode ser aplicável a outros gêneros fotográficos circulantes na cultura midiática, em especial, nas redes sociais. Evidentemente, a metodologia aqui apresentada é uma opção, entre outras, que os pesquisadores da imagem podem aplicar ou agregar às suas pesquisas. Preocupou-nos, exclusivamente, apresentar uma abordagem para a composição da episteme em torno do autorretrato nas mídias sociais e um método de investigação das imagens no Instagram tendo como ferramenta tecnológica o aparelho celular.

\section{Referências}

BAITELLO JUNIOR, Norval. A era da iconofagia: ensaios de comunicação e cultura. São Paulo: Hacker Editores, 2005.

BARTHES, Roland. A câmara clara: nota sobre fotografia. Tradução: Júlio Catañon Guimarães. Rio de Janeiro: Nova Fronteira, 2000.

BAUMAN, Zygmunt. Modernidade líquida. Rio de Janeiro: Jorge Zahar Ed., 2001. 
BRASIL. Presidência da República. Secretaria de Comunicação Social. Pesquisa brasileira de mídia 2015: hábitos de consumo de mídia pela população brasileira. Brasília: Secom, 2014.

CRUZ, Nina Velasco; ARAUJO, Camila Leite. Imagens de um sujeito em devir: autorretrato em rede. Galaxia, São Paulo, n. 23, p. 111-124, jun. 2012.

GOFFMAN, Erving. A representação do eu na vida cotidiana. Tradução: Maria Célia Santos Raposo. Petrópolis: Vozes, 1985.

HALL, Stuart. A identidade cultural na pós-modernidade. Tradução: Tomaz Tadeu da Silva; Guaracira Lopes Louro. Rio de Janeiro: DP\&A, 2003.

LASCH, Christopher. A cultura do narcisismo: a vida americana numa era de esperanças em declínio. Tradução: Ernani Pavaneli. Rio de Janeiro: Imago, 1983.

MCCRACKEN, Grant. Cultura e consumo: uma explicação teórica da estrutura e do movimento do significado cultural dos bens de consumo. Revista de Administração de Empresas, São Paulo, v. 47, n. 1, p. 99-115, jan./mar., 2007.

RECUERO, Raquel. Redes sociais na internet. Porto Alegre: Sulina, 2009.

ROCHA, Everardo. A mulher, o corpo e o silêncio: a identidade feminina nos anúncios publicitários. ALCEU, v.2 - n.3 - p. 15 a 39 - jul./dez. 2001.

- Representações do consumo: estudos sobre a narrativa publicitária. Rio de Janeiro: Mauad, 2006. 
SCHECHNER, Richard. Between theater and anthropology. Philadelphia: The University of Pennsylvania Press, 1985.

SIBILIA, Paula. O show do eu: a intimidade como espetáculo. Rio de Janeiro: Nova Fronteira, 2008.

SONTAG, Susan. Sobre fotografia. Tradução: Rubens Figueiredo. São Paulo: Companhia da Letras, 2004.

VILLAÇA, Nízia. Personas na Passarela: moda e subjetivação. Logos: Comunicação e Universidade, Rio de Janeiro, v.9. n. 2, 2002 . 